\title{
Erratum to: Hematological and Biochemical Profile of Pike Breeders (Esox lucius Linneaus, 1758) from the Anzali Wetland, Caspian Sea
}

\author{
Milad Adel $^{1} \cdot$ Reza Safari $^{1} \cdot$ Sakineh Yeganeh $^{2} \cdot$ P. Satheesh Kumar $^{3} \cdot$ Pegah Safaie $^{4}$
}

Published online: 28 September 2016

(C) The National Academy of Sciences, India 2016

Erratum to: Proc. Natl. Acad. Sci., India, Sect.

\section{B Biol. Sci.}

DOI 10.1007/s40011-015-0704-9

In the original publication, the affiliation of the author Sakineh Yeganeh is incorrect. The correct name of the university is "Sari Agricultural Sciences and Natural Resources University (SANRU)".

The online version of the original article can be found under doi:10.1007/s40011-015-0704-9.

Milad Adel

miladade185@yahoo.com

1 Department of Aquatic Animal Health and Diseases, Iranian Fisheries Science Research Institute (IFSRI), Agricultural Research Education and Extension Organization (AREEO), Tehran, Iran

2 Department of Fisheries, Sari Agricultural Sciences and Natural Resources University (SANRU), Sari, Iran

3 Department of Biological and Environmental Sciences, University of Messina, 98166 Messina, Italy

4 Department of Clinical Sciences, Faculty of Veterinary Medicine, Shahid Chamran University, Ahvaz, Iran 